\title{
Identification of a mouse ghrelin gene transcript that contains intron 2 and is regulated in the pituitary and hypothalamus in response to metabolic stress
}

\author{
Rhonda D Kineman ${ }^{1,2}$, Manuel D Gahete ${ }^{1,2}$ and Raul M Luque L,2 $^{1,2}$ \\ ${ }^{1}$ Section of Endocrinology, Diabetes and Metabolism, Department of Medicine, University of Illinois at Chicago, Chicago, Illinois, USA \\ ${ }^{2}$ Research and Development Division, Jesse Brown Veteran's Administration Medical Center, Chicago, Illinois, USA \\ (Requests for offprints should be addressed to R M Luque who is now at Research and Development Division, Jesse Brown VA Medical Center, M.P 151, West Side, Suite \#6215, 820 \\ South Damen Avenue, Chicago, Illinois 60612, USA; Email: luque@uic.edu)
}

\begin{abstract}
The mouse ghrelin gene contains 5 exons (Ex), with Ex2-Ex5 encoding a 117 amino acid preproprotein that is processed to yield a 28 amino acid mature peptide. The current study examined if pituitary (PIT) and hypothalamus (HPT) ghrelin expression is up-regulated in response to fasting and down-regulated in obesity, as previously reported in the stomach. In the process of establishing a quantitative real-time RT-PCR system to accurately assess the changes in PIT and HPT ghrelin mRNA levels, we observed that primer sets located in Ex2 and Ex3 amplified a ghrelin transcript that contained the entire intron 2 (In2). Size and sequence analysis of RT-PCR products using multiple primer sets located throughout the ghrelin gene suggested that the In2-ghrelin variant contains Ex2 and Ex3, but lacks Ex1, Ex4, and Ex5. In2-ghrelin variant mRNA was not detected in stomach extracts, while expression levels were 10-and 50-fold greater than that of the native ghrelin transcript in the PIT and HPT respectively. In2-ghrelin variant mRNA levels increased in the PIT after $24 \mathrm{~h}$ fasting and decreased in the HPT and PIT of diet-induced obese mice. These changes may be due to the changes in circulating insulin or IGF-I, since both decreased In2-ghrelin variant expression in a mouse HPT cell line (N6) and in primary mouse PIT cell cultures. The fact that In2-ghrelin variant mRNA levels are dependent on energy intake in the PIT and HPT suggests that this transcript may encode a peptide important in coordinating the neuroendocrine response to metabolic stress.
\end{abstract}

Journal of Molecular Endocrinology (2007) 38, 511-521

\section{Introduction}

Evidence is mounting that ghrelin is an endocrine link connecting physiological processes regulating nutrition, body composition, growth, and energy balance (Tschop et al. 2000, Horvath et al. 2001, Nakazato et al. 2001, van der Lely et al. 2004). Exogenous ghrelin stimulates food intake and promotes energy storage (Tschop et al. 2000, Asakawa et al. 2001, Nakazato et al. 2001). In a number of species including humans, endogenous ghrelin is down-regulated in obesity (Tschop et al. 2001, Sugino et al. 2002, Moesgaard et al. 2004, Luque \& Kineman 2006, Martin et al. 2006) and up-regulated in response to food deprivation (Toshinai et al. 2001, Luque et al. 2006b, 2007).

Ghrelin was originally identified as a 117 amino acid preproprotein that is further processed to yield a 28 amino acid mature peptide (Kojima et al. 1999, van der Lely et al. 2004). The active core amino acid sequence comprises the first five residues of the mature peptide, with Ser3 being acylated (Gly-Ser-Ser(n-octanoyl)Phe-Leu). This acylated peptide is required for the binding and activation of the growth hormone secretagogue receptor 1a (GHS-R1a), which in turn stimulates food intake and energy stores (Bednarek et al. 2000, van der Lely et al. 2004). Non-acylated ghrelin does not bind to the GHS-Rla, but does have biological activities in multiple tissues, through a yet to be identified receptor that is distinct from GHS-R1a (Muccioli et al. 2004, Gauna et al. 2005, Toshinai et al. 2006). In addition to the modification by acylation, the preproghrelin peptide can be differentially processed by enzymatic cleavage (Hosoda et al. 2000a, 2003, Pemberton et al. 2003, Nishi et al. 2005, Zhang et al. 2005). For example, it is now appreciated that preproghrelin can be enzymatically cleaved to yield both ghrelin and obestatin, where obestatin is a 23 amino acid peptide that may act through distinct receptors to oppose the actions of ghrelin (Zhang et al. 2005). In addition to post-translational modification of ghrelin to produce biologically distinct peptides, it has also been documented that the ghrelin gene can produce multiple peptides by alternative splicing (Hosoda et al. 2000b, Tanaka et al. 2001b, Jeffery et al. 2002, 2005, Kawamura et al. 2003). For example, an alternative splice site in the In2 of the ghrelin gene results in the translation of a biologically active peptide identical to mature 
ghrelin, except for the loss of a single glutamine residue at position 14 (des-Gln14-ghrelin; Hosoda et al. 2000b). Also, a testis-specific ghrelin gene-derived transcript (GGDT) has been identified which uses an alternative start site located in In 3 of the ghrelin gene, resulting in a transcript containing a unique exon 1 (Ex1) in-frame with the Ex4 and Ex5 (Tanaka et al. 2001b). Therefore, it is now appreciated that the ghrelin gene is regulated at multiple levels to yield proteins of diverse function.

In the current study, we present data indicating the existence of a truncated spliced mRNA variant of ghrelin containing Ex2, In2, and Ex3, but lacking Ex1, Ex4, and Ex5, named 'In2-ghrelin variant'. This transcript was found to be dominantly expressed in the mouse hypothalamus (HPT) and pituitary (PIT), but was not detectable in the stomach. Physiologic relevance of In2-ghrelin variant is supported by the fact that mRNA levels are regulated in response to metabolic stress (fasting and obesity) in a tissuedependent fashion.

\section{Materials and methods}

\section{Animals and cell culture}

All experimental procedures were approved by the Animal Care and Use Committees of the University of Illinois at Chicago and the Jesse Brown VA Medical Center. C57Bl/6J mice were purchased from Jackson Laboratories (Bar Harbor, ME, USA), while C57Bl/6J $\times$ FVBN mice were generated from an in-house breeding colony. All mice were housed under a ratio of $12 \mathrm{~h}$ light:12 h darkness (lights on $0700 \mathrm{~h}$ ) with free access to standard rodent chow (LabDiet, Framingham, MA, USA, Cat\#5008) and tap water unless specified. Mice were handled daily, at least 1 week prior to euthanasia (between 0800 and $1000 \mathrm{~h}$ ) to acclimate to personnel and handling procedures. Tissues were collected and frozen in liquid nitrogen and stored at $-80{ }^{\circ} \mathrm{C}$ until analysis of mRNA levels by conventional or quantitative real-time RT-PCR (qrtRT-PCR, see below). The specific use of animals for each phase of the study is indicated below.

\section{Identification of the In2-ghrelin variant}

Initial amplification and sequencing of ghrelin gene transcripts were performed by standard and qrtRT-PCR using tissue extracts (HPT, PIT, and stomach) from $\mathrm{C} 57 \mathrm{Bl} / 6 \mathrm{~J}$ or $\mathrm{C} 57 \mathrm{Bl} / 6 \mathrm{~J} \times \mathrm{FVBN}$ male and females mice (2-6 months of age).

\section{Comparison of In2-ghrelin mRNA levels between males and females}

Male and female $\mathrm{C} 57 \mathrm{Bl} / 6 \mathrm{~J}$ mice were killed at 10 weeks of age by decapitation under fed conditions.

\section{Effect of fasting on In2-ghrelin expression}

$\mathrm{C} 57 \mathrm{Bl} / 6 \mathrm{~J}$ male mice at 10 weeks of age were weighed and food was withdrawn $(0800-0900 \mathrm{~h})$ from a subset of mice, while the remaining received food ad libitum. After $24 \mathrm{~h}$, mice were killed by decapitation.

\section{Regulation of In2-ghrelin variant in the obese state}

To evaluate the effect of diet-induced obesity (DIO) on PIT and HPT ghrelin gene expression, tissue samples were used from mice fed a low-fat (LF) or a high-fat (HF) diet as previously reported (Luque \& Kineman 2006). Briefly, $\mathrm{C} 57 \mathrm{Bl} / 6 \mathrm{~J}$ male mice were placed on either a LF ( $10 \% \mathrm{kcal}$ from fat) or HF ( $60 \% \mathrm{kcal}$ from fat) diet at 4 weeks of age and killed at 20 weeks of age. HF-fed mice were found to be significantly heavier than LF-fed controls. The dramatic weight gain in HF-fed mice was associated with an increase in total calories consumed, an elevation in circulating insulin and glucose levels, as well as an increase in subcutaneous-, visceral-, and intraabdominal fat mass (Luque \& Kineman 2006).

Effect of insulin and insulin-like growth factor I (IGF-I) on In2-ghrelin expression in a mouse hypothalamic cell line (N6) and in primary PIT cell cultures

In order to investigate whether the In2-ghrelin variant mRNA levels could be directly regulated by metabolic hormones in hypothalamic cells, we used the hypothalamic cell line N6 (CELLutions Biosystems Inc., Toronto, Ontario, Canada), originally developed by Belsham et al. (2004) with a detailed expression profile provided at www.cellutionsbiosystems.com/n6.php. This cell line was maintained in our laboratory according to previously described methods (Belsham et al. 2004). Primary PIT cell cultures were prepared by enzymatic dispersion of 3-4 pituitaries/experiment from 8- to 10-week-old male mice, as previously described by our laboratory (Luque \& Kineman 2006, Luque et al. 2006b).

For in vitro experiments, $\mathrm{N} 6$ cells and primary PIT cells were cultured in monolayer at $2 \times 10^{5} /$ well in $\alpha$-minimum essential media (MEM; Invitrogen Life Technologies, Inc., Grand Island, NY, USA) containing $2.5 \%$ fetal bovine serum (FBS; Sigma), $0 \cdot 1 \%$ BSA (Sigma), $6 \mathrm{mM} \mathrm{N}$-2-hydroxyethylpiperazine-N-2-ethanesulfonic acid (HEPES; Invitrogen), $125 \mathrm{nM}$ transferrin (Sigma), $0.6 \mathrm{nM}$ tri-iodothyronine (Sigma), $275 \mathrm{nM}$ hydrocortisone (Sigma), and $1 \%$ penicillin-streptomycin antibiotic (Invitrogen) and maintained at $37^{\circ} \mathrm{C}$ in an atmosphere of $5 \% \mathrm{CO}_{2}$. After $24 \mathrm{~h}$ incubation, cultures were preincubated in serum-free medium for $2 \mathrm{~h}$ and subsequently the medium was replaced with serum-free medium containing 0 (control group) or $10 \mathrm{nM}$ insulin or IGF-I (3-4 wells/treatment group). Cultures were incubated for an additional $24 \mathrm{~h}$ and total RNA recovered (see below). 


\section{RNA isolation and reverse transcription}

Tissues or cell cultures were processed for recovery of total RNA using the Absolutely RNA RT-PCR Miniprep kit (Stratagene, La Jolla, CA, USA), with DNase treatment as previously described (Luque \& Kineman 2006, Luque et al. 2006a,b). The amount of RNA recovered was determined using the Ribogreen RNA quantification kit (Molecular Probes, Eugene, OR, USA). Total RNA ( $1 \mu \mathrm{g}$ for whole tissue extract and $0 \cdot 25 \mu \mathrm{g}$ for primary cell cultures) was reverse transcribed, in a $20 \mu \mathrm{l}$ volume using random hexamer primers, with enzyme and buffers supplied in the cDNA First-Strand Synthesis kit (Fermentas, Hanover, MD, USA). cDNA was treated with ribonuclease $\mathrm{H}$ (1 U; MRI Fermentas).

\section{Primer selection and standard or qrtRT-PCR}

Primers used for standard and real-time RT-PCRs (Table 1) were selected using the mouse ghrelin gene sequence as template (Genbank accession \# AB060078) and primer 3 software (http://frodo.wi.mit.edu/cgibin/primer3/primer3_www.cgi; Steve Rozen, Whitehead Institute for Biomedical Research, Cambridge, CA, USA). Sequences of selected primers were used in Basic local alignment search tool (BLAST; NCBI, Bethesda, MD, USA) searches to check for potential homology to sequences other than the designated target. Primers were then used in a standard PCR with the $2 \times$ Master Mix PCR reagent (MRI Fermentas) and cDNA from the tissue of interest as template. Amplification was performed using the Perkin-Elmer

Table 1 Mouse-specific primers for ghrelin used for standard RT-PCR or quantitative real-time RT-PCR

Nucleotide position

\section{Primer sequence}

Sense: GCTGTCTTCAGGCACCATCT

Sense: CTCAGCATGCTCTGGATGGA

Sense: GTCATCTGTCCTCACCACCAA

Sense: ACATCCCCAGGCATTCCAG

Sense: TCCAAGAAGCCACCAGCTAA

Sense: TCAGGTTCAATGCTCCCTTC

Sense: CAATGCTCCCTTCGATGTTG

Antisense: GTGGCTTCTTGGATTCCTTTC

Antisense: AGAGCTCGTGGCTGCAGTTTA

Antisense: GTAGATGTGGGGGCTTAGGG

Antisense: TTCTCTCTCTCTCACACACACACAC

Antisense: CTCTCTCTCTCACACACACACACA

Antisense: CCTTTCTCTGCTGGGCTTTC

Antisense: AACATCGAAGGGAGCATTGA

Antisense: GCGCCTCTTTGACCTCTTC

Antisense: AGGCCTGTCCGTGGTTACTT
GeneAmp PCR System 9600 (Perkin-Elmer, Downers Grove, IL, USA). The final volume of the PCR was $25 \mu \mathrm{l}: 1 \mu \mathrm{l}$ RT sample (50 ng cDNA), $12.5 \mu \mathrm{l}$ of the $2 \times$ Master Mix, $1 \mu \mathrm{l}$ of each primer $(20 \mu \mathrm{M}$ stock solution; $1.25 \mu \mathrm{M})$, and $9.5 \mu \mathrm{ld} \mathrm{d}_{2} \mathrm{O}$. The thermocycling profile consisted of one cycle of $95^{\circ} \mathrm{C}$ for $10 \mathrm{~min}$, followed by 30-40 cycles of $95^{\circ} \mathrm{C}$ for $1 \mathrm{~min}, 61^{\circ} \mathrm{C}$ for $1 \mathrm{~min}$, and $72{ }^{\circ} \mathrm{C}$ for $1 \mathrm{~min}$, and a final cycle of $72^{\circ} \mathrm{C}$ for $10 \mathrm{~min}$. Products were run on agarose gels and stained with ethidium bromide to confirm that only one band, of the expected size, was amplified. These PCR products were then column-purified (Qiagen, Valencia, CA, USA) and sequenced to confirm target specificity.

Initial screening of primer sets for qrtRT-PCR amplification was performed by amplifying twofold dilutions of RT products where optimal efficiency was demonstrated by a difference of 1 cycle threshold (CT) between dilutions. Following confirmation of primer efficiency and specificity, the concentration of purified products (generated by standard PCR and purified for sequencing as described above) was determined using Molecular Probe's Picogreen DNA quantification kit and the PCR products were serial diluted to obtain standards containing $10^{1}, 10^{2}, 10^{3}, 10^{4}, 10^{5}$, and $10^{6}$ copies of synthetic cDNA template per microliter. Standards for native ghrelin were prepared using stomach and PIT cDNA as template (Sn1432, As3499), while standards for In2-ghrelin variant were prepared using PIT cDNA as template (Sn1221, As1444). Standards were then amplified by real-time and standard curves generated by the Stratagene Mx3000p Software. The slope of a standard curve for each template examined was approximately 1 , indicating that the efficiency of amplification was $100 \%$, meaning all templates in each cycle were copied. For real-time PCRs, Brillant SYBR Green QPCR Master Mix (Stratagene) was used, where thermocycling and fluorescence detection were performed using a Stratagene Mx3000p real-time PCR machine. The final volume of the PCR was $25 \mu \mathrm{l}: 1 \mu \mathrm{l}$ RT sample (50 ng cDNA from the tissue of interest), $12.5 \mu \mathrm{l}$ QPCR Master Mix, $0.375 \mu \mathrm{l}$ of each primer $(10 \mu \mathrm{M}$ stock solution; $0.67 \mu \mathrm{M}), 0.375 \mu \mathrm{l}$ reference dye, and $10 \cdot 375 \mu \mathrm{l} \mathrm{dH}_{2} \mathrm{O}$. Thermal cycling profile consisted of a preincubation step at $95^{\circ} \mathrm{C}$ for $10 \mathrm{~min}$, followed by 40 cycles of denaturation $\left(95^{\circ} \mathrm{C}\right.$, $30 \mathrm{~s})$, annealing $\left(61^{\circ} \mathrm{C}, 1 \mathrm{~min}\right)$, and extension $\left(72^{\circ} \mathrm{C}\right.$, $30 \mathrm{~s})$. Final PCR products were subjected to graded temperature-dependent dissociation to verify that only one product was amplified. PCR products were then column-purified and sequenced again to confirm target specificity. To determine the starting copy number of cDNA, RT samples were PCR amplified and the signal compared with that of synthetic cDNA standard curve run on the same plate as previously described (Luque \& Kineman 2006, Luque et al. 2006b). In addition, total RNA samples that were not reverse transcribed and a 
non-DNA control were run on each plate to control for genomic DNA contamination and monitor potential exogenous contamination respectively. In addition, to control for variations in the amount of RNA used in the RT reaction and the efficiency of the RT reaction, mRNA copy number of the transcript of interest was adjusted by that of cyclophilin A (a peptidyl isomerase) as previously described (Luque \& Kineman 2006, Luque et al. 2006b). Cyclophilin A mRNA levels did not significantly vary between experimental groups within tissue type.

\section{Statistical analysis}

Samples from all groups within an experiment were processed at the same time and therefore the in vivo effects of gender and diet and the in vitro effects of insulin and IGF-I on native ghrelin and In2-ghrelin variant were assessed by Student's $t$-test. $P<0.05$ was considered significant. All values are expressed as means \pm s.E.M. All statistical analyses were performed using the GB-STAT software package (Dynamic Microsystems, Inc. Silver Spring, MD, USA).

\section{Results and discussion}

\section{Identification of the In2-ghrelin variant using standard RT-PCR}

The mouse ghrelin gene contains Ex5 with Ex2-Ex5 encoding the preproghrelin as illustrated in Fig. 1A. A set of PCR primers located in Ex2 (Sn 1221) and Ex3 (As 1444) of the mouse ghrelin gene were initially selected to study the regulation of expression in the PIT and HPT under different physiological conditions. Using stomach cDNA as a template, this primer set generated a PCR product that was found to be of the expected size (131 bp) and sequence (Fig. 1B, primer set 1 and $\mathrm{C}$ ). However, when this same primer set was used to amplify PIT and HPT cDNA, a single PCR product was generated that was approximately $100 \mathrm{bp}$ larger than the expected size (226 bp; Fig. 1C). This PCR product did not appear using RNA samples that were not reverse transcribed or in PCRs that did not contain samples, indicating that it was not the result of genomic or reagent contamination respectively (Fig. 1C). DNA sequencing revealed that this product contained the entire In 2 of the mouse ghrelin gene. This larger product could also be amplified using an additional set of primers located within Ex2 (Sn 1255) and Ex3 (As 1469; Fig. 1B, primer set 2). It should be noted that at 30 cycles in a conventional PCR, both Ex2 and Ex3 primer sets only generated a visible band corresponding to the In2-ghrelin variant in the PIT and HPT. However, by increasing the cycle number $(\geq 35$ cycles), a second band appeared corresponding to native ghrelin (i.e., lacking In2), thus suggesting that the In2-ghrelin is the dominant ghrelin gene transcript in the PIT and HPT. The In2-ghrelin variant could also be amplified using two different sets of primers where the sense primer was located in Ex2 and the antisense primer was located in In2 (see Fig. 1B, primer sets 3 and 4 and Fig. 1D). This PCR product could not be amplified if stomach cDNA was used as a template (data not shown). When an antisense primer spanning Ex2/Ex3 (As 1429) was paired with a sense primer located in Ex2 (Sn1194; Fig. 1B, primer set 5), only a faint band could be detected in HPT and PIT cDNA samples, corresponding to the expected size and sequence of the native ghrelin (not containing the In2; data not shown), confirming that native ghrelin is expressed in the HPT and PIT, but only at low levels.

Sequence analysis was performed on PCR products generated from multiple PIT and HPT cDNA samples. This analysis consistently revealed that, in the HPT and PIT, the dominant ghrelin transcript included In2, where the intron sequence differed from that originally reported by Tanaka et al. (2001 $a$; Genbank accession \# AB060078) by $2 \mathrm{bp}$. Specifically, our sequence included eight TG nucleotides repeated in tandem in the middle of the In2 of the mouse ghrelin gene, starting at nucleotide position 1370 (Fig. 1E), while Tanaka et al. (2001a) reported seven TG repeats. The sequence of the In2-ghrelin variant was submitted to Genbank (accession \# DQ993169). Our sequence data proved to be identical to that of a mouse chromosome 6 clone that contained the ghrelin gene (Genbank accession \# AC117596). Therefore, if we assume that the start of transcription is unaltered in the In2-ghrelin variant, inclusion of In2 would encode a premature stop codon (TGA) in position 1384 (Fig. 1E). A truncated transcript is supported by our observations that sense primers located in Ex2, Ex3, Ex4, or Ex3-Ex4 and antisense primers located in Ex4 or Ex5 only amplified the native ghrelin transcript (see Fig. 1B, primer sets 6 10 and Fig. 2B). It should also be noted that using sense primers located in Ex1 (Sn 766) combined with antisense primers located in Ex3 (As 1444), Ex4 (As 3499), or Ex5 (As 4404; Fig. 1B, primers sets 11-13) only amplified the native ghrelin transcript. Also, no PCR product was generated if sense primers located in Ex1 (Sn766) were combined with antisense primers located in In2 (As1362 and As1395; Fig. 1B, primers sets 14 and 15). Collectively, these findings indicate that the In2-ghrelin variant does not include Ex1. However, it should be noted that Ex1 has been identified as a $5^{\prime}$ untranslated region (Tanaka et al. 2001a), where its exclusion would not modify the predicted start codon located at nucleotide position 1219 (Genbank \# AB060078). Therefore, we speculate that the In2ghrelin variant would encode a protein that includes 
A

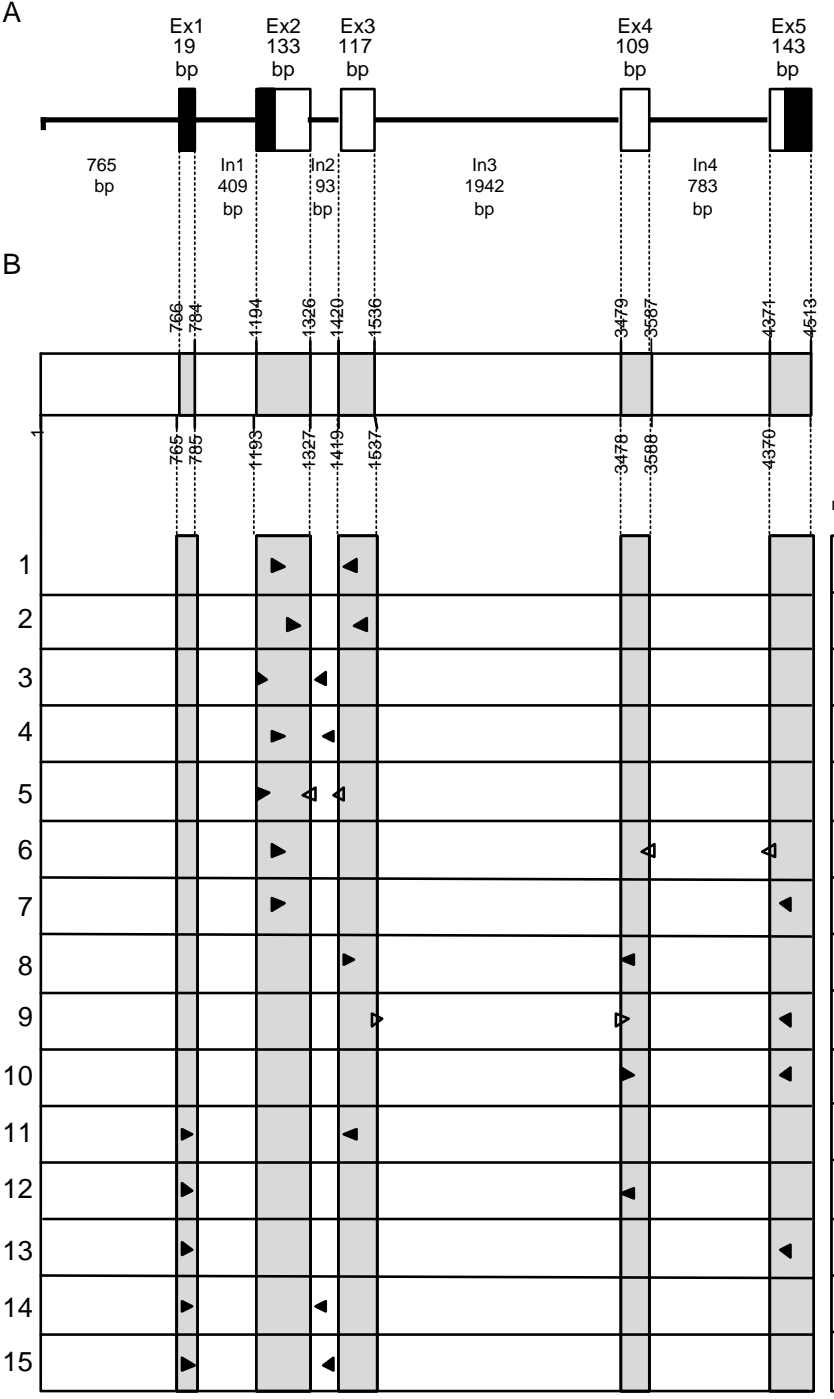

C
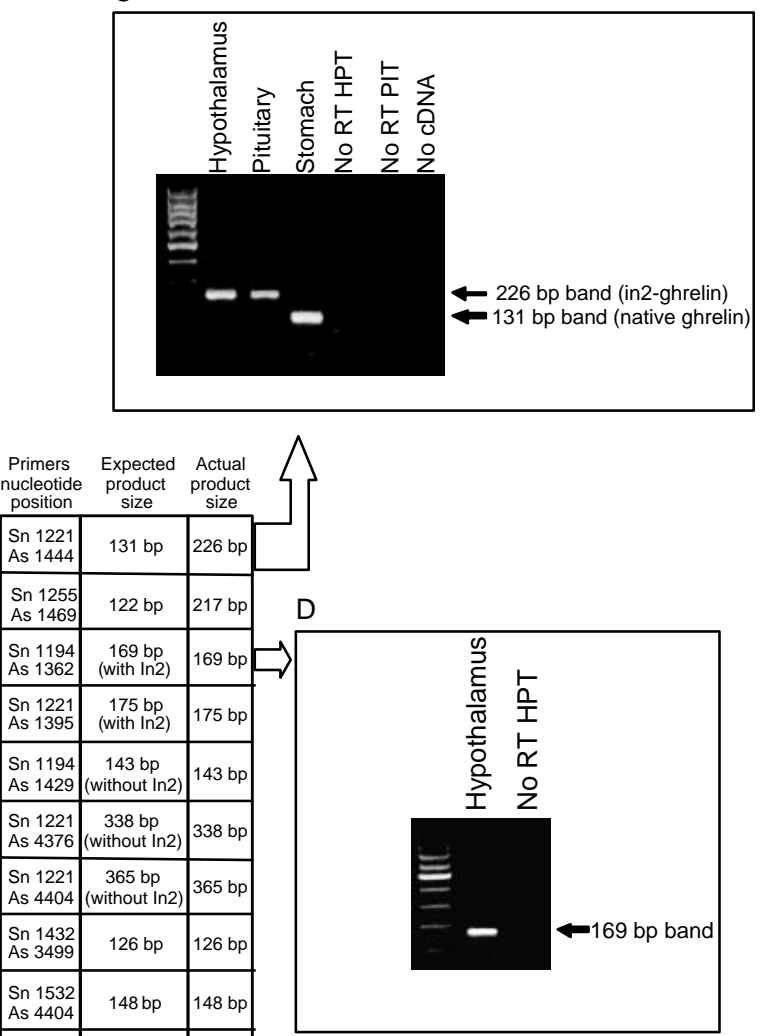

E

Predicted start codon

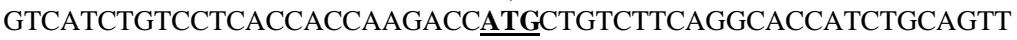

\section{TGCTGCTACTCAGCATGCTCTGGATGGACATGGCCATGGCAGGCTCCAGCTTC}

\section{CTGAGCCCAGAGCACCAGAAAGCCCAGGTCAGTCAGTCTGTCTCCCTAAGCC}

\section{CCCACATCTACCCCGATCTGTGTGTGTGTGTGTGAGAGAGAGAGAAAGAGAA \\ PPredicted stop codon \\ CCCTCTTTTCCTTTCCAGCAGAGAAAGGAATCCAAGAAGCCACCAGCTAAAC}

\section{TGCAGCCACGAGCTCT}

Figure 1 (A) Schematic representation of mouse ghrelin gene. Exons are shown by boxes (black boxes indicate the $5^{\prime}$ and $3^{\prime}$ non-coding regions and white boxes indicate the coding region). This scheme is based on Genbank accession \# AB060078 (Tanaka et al. 2001a). (B) Nucleotide numbers indicating the boundaries of the introns/exons in the mouse ghrelin gene (exons are indicated by shaded boxes). Arrow heads are used to indicate the relative positions of primer sets. Closed arrows indicate primers within exons, while open arrows indicate primers spanning exons. (C) Representative agarose gel showing PCR products amplified for 30 cycles using primers located in Ex2 (Sn1221) and Ex3 (As1444) with standard PCR conditions. (D) Representative agarose gel showing PCR products amplified for 35 cycles using primers located in Ex2 (Sn1194) and In2 (As1362) with standard PCR conditions. All products were size separated on an agarose gel containing $\mathrm{EtBr}$, column-purified, and sequenced to confirm target specificity. (E) Nucleotide sequence of the In2-ghrelin variant (accession \# DQ993169) with the putative start and stop codons underlined and the In2 sequence shaded. 
A

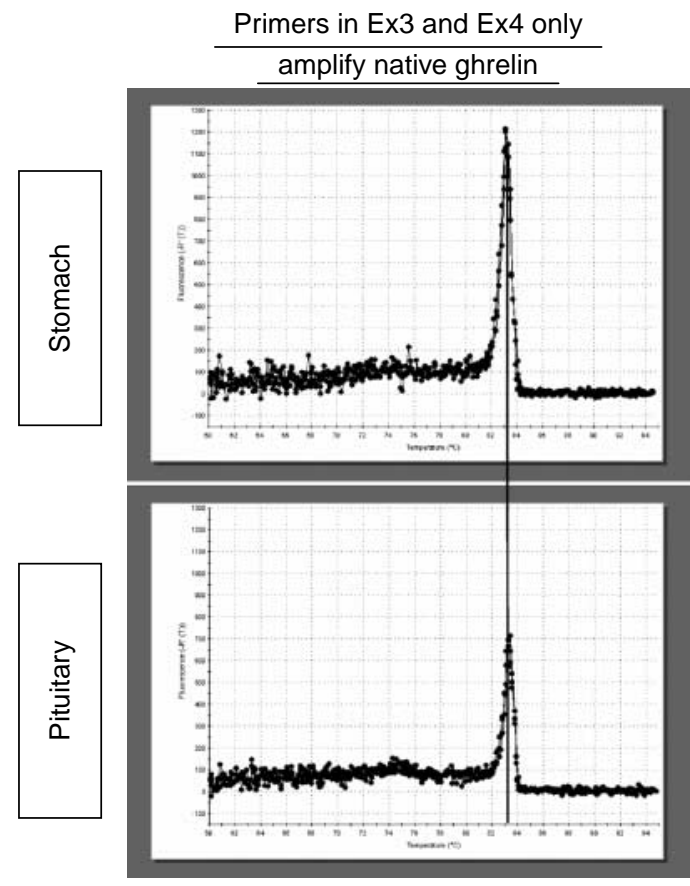

B

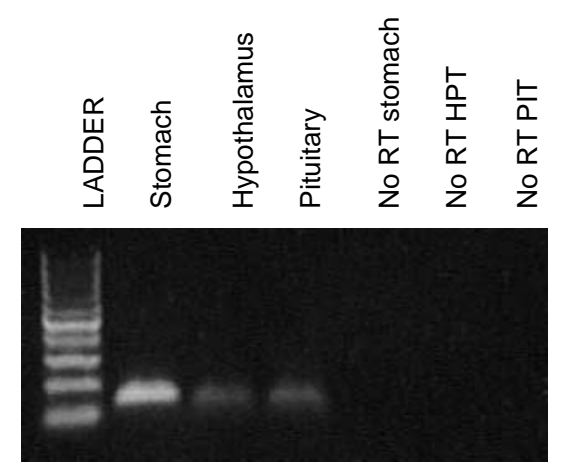

C
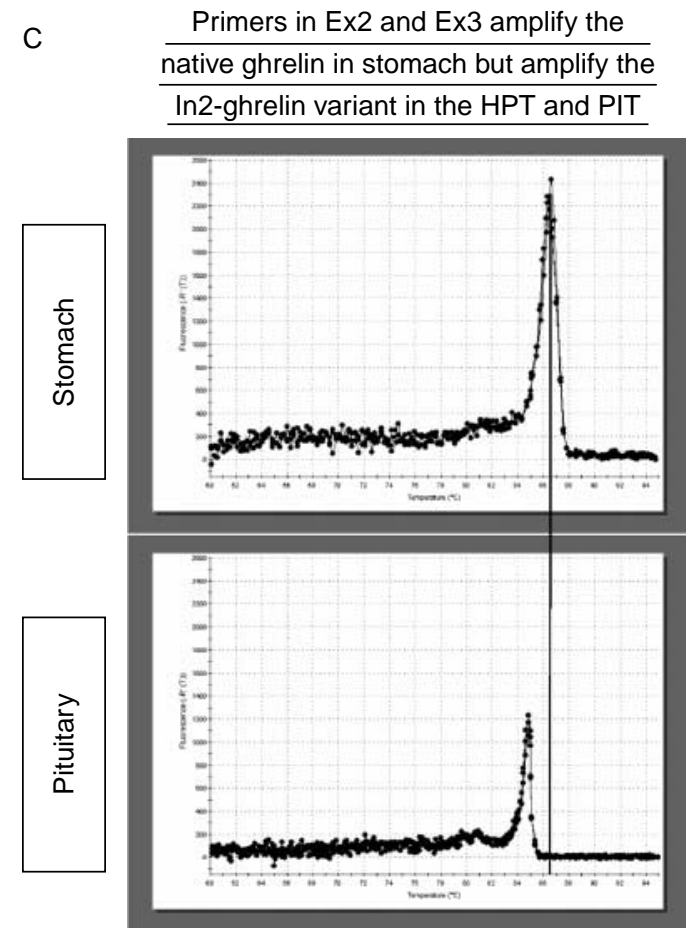

D

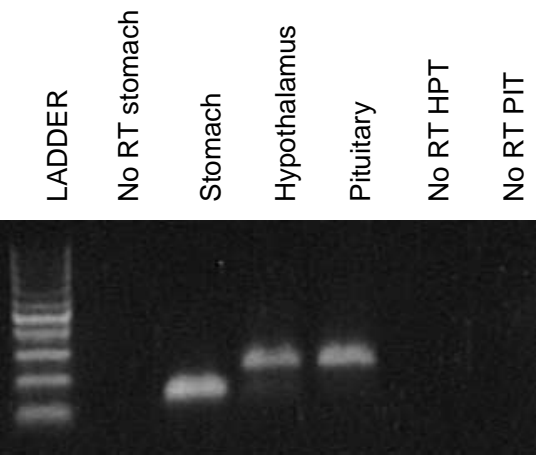

Figure 2 (A) Dissociation curves of qrtRT-PCR products (40 cycles) with identical $T_{m}$ of dissociation $\left(83.2^{\circ} \mathrm{C}\right.$ ), generated from the stomach and PIT, using primers located in Ex3 (Sn1432) and Ex4 (As3499). (B) Agarose gel separation of qrtRT-PCR products generated from stomach, HPT, and PIT using primers located in Ex3 (Sn1432) and Ex4 (As3499). (C) Dissociation curves of qrtRT-PCR products (40 cycles) generated from the stomach and PIT with different $T_{\mathrm{m}}$ of dissociation $\left(86.6^{\circ} \mathrm{C}\right.$ in stomach vs $84.7^{\circ} \mathrm{C}$ in PIT), using primers located in Ex2 (Sn1221) and Ex3 (As1444). (D) Agarose gel separation of qrtRT-PCR products generated from stomach, HPT, and PIT using primers located in Ex2 (Sn1221) and Ex3 (As1444).

the first 36 amino acids of the preproghrelin, where residues 24-28 (Gly-Ser-Ser-Phe-Leu) represent the first five amino acids of the mature peptide, while the C-terminal tail would be a novel 19 amino acid sequence encoded by In2 (VSQSVSLSPHIYPDLCVCV). If this is indeed the case, obestatin, which is thought to oppose the GHS-R mediated actions of ghrelin (Zhang et al. 2005), would not be produced. Therefore, if the protein product of In2-ghrelin has similar functions to that of native ghrelin, we might speculate that its actions would go unopposed in the mouse HPT and PIT. However, we cannot say at this time if the putative protein of the In2-ghrelin variant can be acetylated and appropriately activate GHS-R1a (Kojima et al. 1999, van der Lely et al. 2004).

It is well known that regulation at different levels of the ghrelin gene contributes significantly to protein diversity in several species, including human and mouse (Hosoda et al. 2000a,b, 2003, Tanaka et al. 2001b, Jeffery et al. 2002, 2005, Kawamura et al. 2003, Pemberton et al. 
2003, Nishi et al. 2005, Zhang et al. 2005, Gualillo et al. 2006). Consistent with the alternative usage of In2 observed in the current report, utilization of an alternative splice site in In2 has previously been reported to yield 'des-Gln ${ }^{14}$-ghrelin' in several species (Hosoda et al. 2000b, 2003, Kawamura et al. 2003; Genbank \#: AB089202). In addition, consistent with the current study, Jeffery et al. (2005) recently reported the expression of a ghrelin variant that retains the coding sequence for mature ghrelin but has a novel C-terminal tail due to the exclusion of Ex4 resulting in a cDNA frameshift that generates a premature stop codon. The same group previously identified a human homolog of this isoform that is expressed in a wide range of human tissues (Jeffery et al. 2002). Another example of the alternative usage of an intron within the ghrelin gene is the report by Tanaka et al. (2001b), who identified an alternative splice variant of the ghrelin gene in the mouse testis, GGDT, that is derived from a start codon located in the In3. Therefore, evidence is accumulating that the ghrelin gene can be differentially regulated at multiple levels (transcriptional, translational, and posttranslational).

\section{Verification and quantification of the In2-ghrelin variant and native ghrelin expression using standard and qrtRT-PCR}

Next, we wanted to accurately compare the level of expression of the In2-ghrelin variant with that of native ghrelin. As discussed above, our data indicate that the In2-ghrelin variant lacks Ex4 and Ex5. Therefore, a set of primers located in Ex3 and Ex4 were used to amplify native ghrelin (Fig. 1B, primer set 8). Using this primer set in a qrtRT-PCR, products were obtained in the stomach and PIT (Fig. 2A) and HPT (data not shown) that had identical temperature-dependent dissociation $\left(T_{\mathrm{m}} \sim 83.2^{\circ} \mathrm{C}\right)$. When the same samples were size separated in an ethidium bromide containing agarose gel, single bands of similar size were visualized (Fig. 2B), which proved to have identical sequences. To amplify the In2-ghrelin variant, a primer set located in Ex2 and Ex3 was selected (Fig. 1B, primer set 1). Using this primer set in a qrtRT-PCR, a single product was obtained in all tissues; however, the temperature of dissociation varied $\left(86.6{ }^{\circ} \mathrm{C}\right.$ in stomach vs $84.7^{\circ} \mathrm{C}$ in $\mathrm{HPT}$ and PIT), indicating a different product was generated in the HPT and PIT compared with the stomach (Fig. 2C), as confirmed by gel separation of the qrtRT-PCR products (Fig. 2D) and sequence analysis. These data demonstrate that under the conditions tested, the qrtRT-PCR primer sets for native ghrelin and In2-ghrelin variant were appropriate to perform quantitative analysis of ghrelin isoform expression in the HPT and PIT. Therefore, using qrtRT-PCR analysis, we found that mRNA levels for the In2-ghrelin variant were in the order of
Table 2 Absolute cDNA copy number/0.05 $\mu \mathrm{g}$ total RNA of ghrelin gene transcripts in the hypothalamus, pituitary, and stomach of male and female $\mathrm{C} 57 \mathrm{BI} / 6$ mice, as determined by quantitative real-time RT-PCR. Values represent means \pm S.E.M. ( $n=5-12$ tissues/group)

\begin{tabular}{|c|c|c|}
\hline & Males & Females \\
\hline \multicolumn{3}{|l|}{ Hypothalamus } \\
\hline Native ghrelin & $26 \pm 2$ & $27 \pm 6$ \\
\hline In2-ghrelin variant & $948 \pm 166$ & $1336 \pm 300$ \\
\hline \multicolumn{3}{|l|}{ Pituitary } \\
\hline Native ghrelin & $18 \pm 3$ & $19 \pm 7$ \\
\hline In2-ghrelin variant & $139 \pm 24$ & $122 \pm 31$ \\
\hline \multicolumn{3}{|l|}{ Stomach } \\
\hline Native ghrelin & $197933 \pm 4627$ & $190880 \pm 18293$ \\
\hline In2-ghrelin variant & Not detected & Not detected \\
\hline
\end{tabular}

50- and 10-fold greater in the HPT and the PIT than that of the native ghrelin transcript in both male and female mice (Table 2) respectively, confirming that In2-ghrelin variant is the dominant ghrelin isoform in the HPT and PIT and that the expression of this transcript is not gender-dependent under fed conditions.

\section{Metabolic regulation of the In2-ghrelin variant}

We have previously reported that fasting up-regulates the expression of native ghrelin in the mouse PIT, but has no effect on HPT mRNA levels (Luque et al. 2006b, 2007). Consistent with these findings, in the current report, we observed that the expression of both native ghrelin (Fig. 3A) and In2-ghrelin variant (Fig. 3B) increased after $24 \mathrm{~h}$ fasting in the PIT, whereas HPT expression was resistant to this metabolic stimulus. In contrast to the parallel regulation of native ghrelin and In2-ghrelin variant in the PIT in response to fasting, excess nutrient intake (HF-fed mice) which was previously reported to increase fat mass and elevate circulating insulin levels (Luque \& Kineman 2006), led to a significant suppression of only the In2-ghrelin variant in the HPT and PIT (Fig. 4A and B), indicating that native ghrelin and In2ghrelin variant mRNA can be differentially regulated depending of the metabolic insult. Differential metabolic regulation of stomach native ghrelin transcript (the main transcript produced in the stomach) has also been reported by us (Luque et al. 2006b, 2007) and others (Moesgaard et al. 2004). Specifically, fasting does not alter the expression of native ghrelin in the stomach (Moesgaard et al. 2004, Luque et al. 2006b, 2007), while HF diet does significantly suppress stomach mRNA levels (Moesgaard et al. 2004).

The question arises, which factors may contribute to the regulation of HPT and PIT ghrelin expression in response to metabolic stress? One factor may be insulin, since it is down-regulated in response to fasting and up-regulated in states of obesity and has previously been 

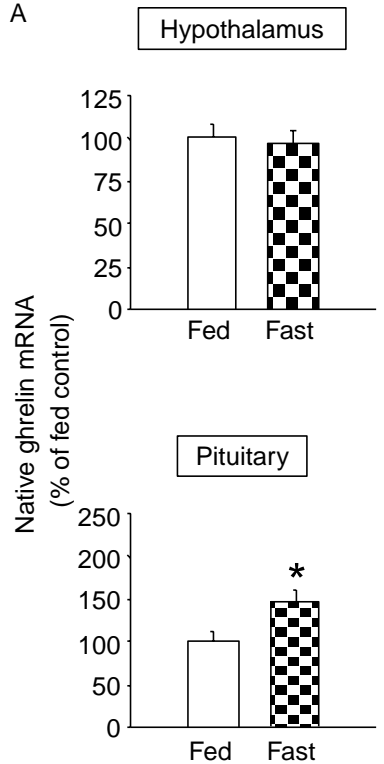

Hypothalamus

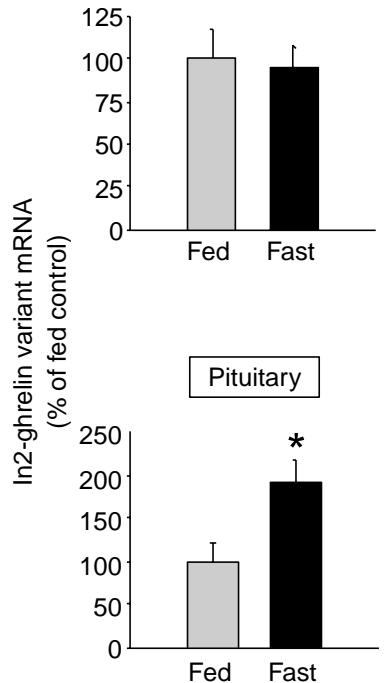

Figure 3 Tissue-dependent expression levels of native ghrelin (A) and In2ghrelin variant (B) in fed and 24-h fasted mice ( $n=7$ mice per group). Both ghrelin transcripts mRNA copy numbers were corrected by cyclophilin A mRNA copy number and values are shown as the mean \pm s.E.M. mRNA values are expressed as percent of fed controls (set at $100 \%)$. *Values that differ from fed controls. $P<0.05$ was considered significant.

A
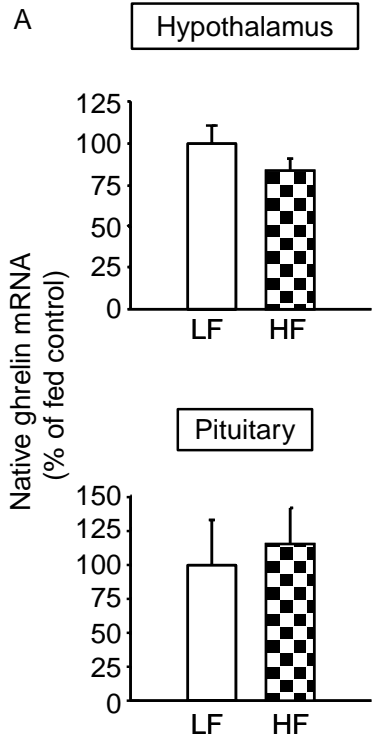

B

Hypothalamus

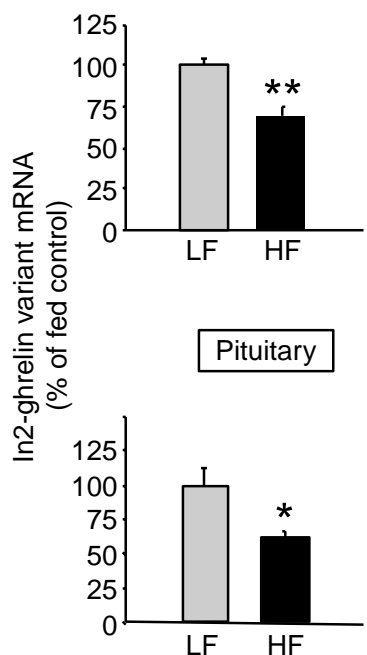

Figure 4 Hypothalamic and pituitary native ghrelin $(A)$ and In2ghrelin variant $(B)$ mRNA levels of $C 57 B L / 6 \mathrm{~J}$ male mice fed a low-fat (LF) or high-fat (HF) diet for 16 weeks (starting at 4 weeks of age; $n=$ 6-7 mice per group). Both ghrelin transcripts mRNA copy numbers were corrected by cyclophilin A mRNA copy number and values are shown as means \pm S.E.M. mRNA values are expressed as percent of LF diet control mice (set at $100 \%)$. Asterisks ( ${ }^{\star} P<0.05,{ }^{\star \star} P<0.01$ ) indicate values that differ from fed controls. 
reported to negatively regulate the synthesis and release of ghrelin from the stomach (Kamegai et al. 2004). Therefore, we sought to determine if insulin could also have a direct inhibitory effect on PIT and HPT ghrelin expression. In addition, we examined the direct effect of IGF-I because the levels of 'free' IGF-I have been reported, by some, to be elevated in obesity (Frystyk et al. 1999, Ricart \& Fernandez-Real 2001), where the insulin and IGF-I receptors share significant structural homology, are activated by their respective ligands at high doses, and can signal through common intracellular signal transduction pathways (for review, see Nakae et al. 2001).

To this end, we utilized a mouse HPT cell line (N6) developed by Belsham et al. (2004) using retroviral transfer of SV-40 T-antigen into primary fetal mouse hypothalamic cell cultures. In our hands, these cells expressed native ghrelin and In2-ghrelin variant mRNA by conventional PCR (Fig. 5A). Use of qrtRT-PCR indicated that In2-ghrelin variant is expressed in N6 cells at levels comparable with those in whole mouse HPT extracts (N6 cells vs mouse HPT: $24 \pm 4$ vs $20 \pm 4$ copies/ $0.05 \mu \mathrm{g}$ total RNA for native ghrelin and $629 \pm 33$ vs $1147 \pm 198$ copies $/ 0 \cdot 05 \mu \mathrm{g}$ total RNA for In2-ghrelin variant). It should be noted that both primary PIT cell cultures and N6 cells also express insulin and IGF-I receptors at levels comparable with those in whole mouse PIT and extracts (data not shown). Insulin and IGF-I $(24 \mathrm{~h})$ inhibited In2-ghrelin variant mRNA in N6 cells (Fig. 5B). However, native ghrelin expression levels were not significantly altered (Fig. 5B). To examine the direct effect of insulin and IGF-I on the PIT, we utilized primary mouse PIT cell cultures which expressed In2-ghrelin variant mRNA at levels comparable with whole PIT extracts (primary cell culture vs mouse PIT: $203 \pm 85$ vs $130 \pm 19$ copies $/ 0 \cdot 05 \mu \mathrm{g}$ total RNA); however, native ghrelin was not detectable in cultured cells. The lack of native ghrelin expression in primary PIT cell cultures is not surprising based on the low levels of native ghrelin $(<$ 20 copies) observed in whole PIT extract and the fact that the amount of total RNA used to generate cDNA in culture experiments was $75 \%$ less than that used in the studies of whole tissue extracts. Nonetheless, we cannot exclude the possibility that enzymatic dispersion and culture of primary cells does not provide the same environment as found in vivo to support native ghrelin expression. Similar to that observed in the HPT cell line, insulin and IGF-I $(24 \mathrm{~h})$ inhibited In2-ghrelin variant mRNA in PIT cell cultures (Fig. 5C). Taken together, these results suggest that a rise in circulating insulin, which is observed in DIO mice (Luque \& Kineman 2006), may be directly responsible for suppressing In2-ghrelin expression in both the HPT and PIT.

In summary, we report for the first time the existence of a spliced mRNA variant of the ghrelin gene containing Ex2, In2, and Ex3, but lacking Ex1, Ex4,
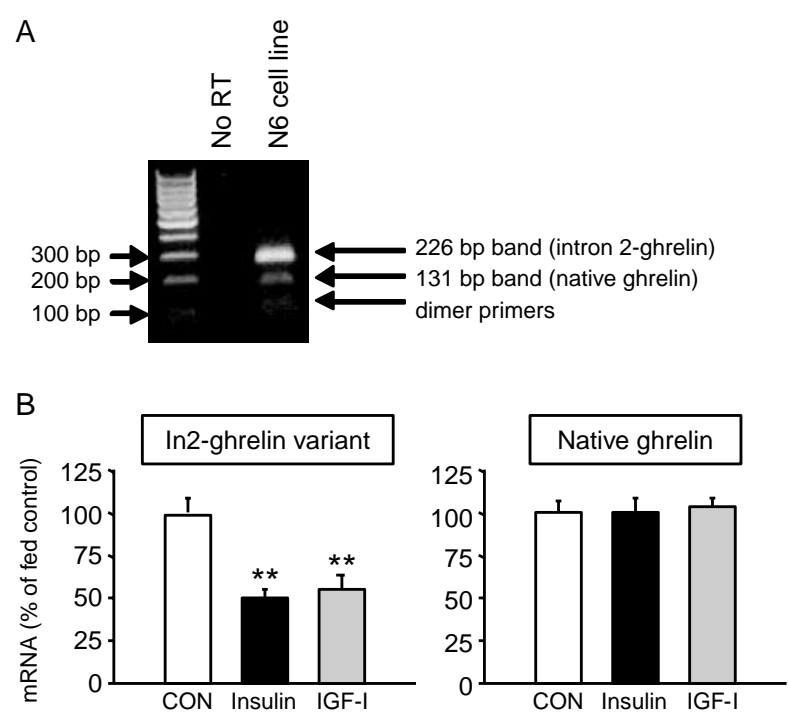

C

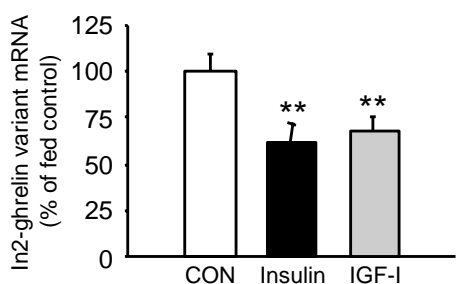

Figure 5 (A) Agarose gel of RT-PCR products generated using cDNA from a mouse hypothalamic cell line, N6, as template and primers located in Ex2 (Sn1221) and Ex3 (As1444). The upper band (226 bp) corresponds to mRNA for In2-ghrelin variant, the middle band (131 bp) corresponds to mRNA for native ghrelin, and the lower band corresponds to primer dimers. It should be noted that this PCR was performed with 40 cycles of amplification in order to visualize the native ghrelin transcript. (B) Effect of insulin and IGF-I treatment ( $24 \mathrm{~h} ; 10 \mathrm{nM})$ on In2-ghrelin variant and native ghrelin mRNA levels in mouse N6 cultures. Data represent the mean \pm S.E.M. of three separate experiments performed on different cell preparations. (C) Effect of insulin and IGF-I treatment $(24 \mathrm{~h} ; 10 \mathrm{nM})$ on In2-ghrelin variant mRNA levels in mouse pituitary cell cultures. Data represent the mean \pm S.E.M. of four separate experiments performed on different cell preparations. Native ghrelin transcript was not detectable in primary pituitary cell cultures. All values are expressed as absolute mRNA copy number of In2-ghrelin variant or native ghrelin adjusted by cyclophilin A copy number. Copy number was determined by qrtRT-PCR using primers located in Ex2 (Sn1221) and Ex3 (As1444) to detect In2-ghrelin variant and primers located in Ex3 (Sn1432) and Ex4 (As3499) to detect native ghrelin. ${ }^{*}$ Values that differ from controls. $P<0.01$ was considered significant.

and Ex 5 which is dominantly expressed in the PIT and HPT of the mouse. In2-ghrelin variant may be of biological relevance because it is regulated in extreme metabolic states (fasting and obesity) and its regulation is tissue-dependent. The fact that the levels of In2ghrelin variant mRNA are dependent on energy intake in the PIT and HPT suggests that this transcript may 
encode a peptide important in coordinating the neuroendocrine response to metabolic stress.

\section{Acknowledgements}

This work was supported by the NIH NIDDK 30677 (to R D K), Endocrine Society Summer Fellowship Award (to M D G), and by the 'Secretaria de Universidades, Investigación y Tecnología de la Junta de Andalucia' (to R M L). The authors declare that there is no conflict of interest that would prejudice the impartiality of this scientific work.

\section{References}

Asakawa A, Inui A, Kaga T, Yuzuriha H, Nagata T, Ueno N, Makino S, Fujimiya A, Niijima A, Fujino MA et al. 2001 Ghrelin is an appetitestimulatory signal from the stomach with structural resemblance to motilin. Gastroenterology 120 337-345.

Bednarek MA, Feighner SD, Pong SS, McKee KK, Hreniuk DL, Silva MV, Warren VA, Howard AD, Van Der Ploeg LH \& Heck JV 2000 Structure-function studies on the new growth hormone-releasing peptide, ghrelin: minimal sequence of ghrelin necessary for activation of growth hormone secretagogue receptor 1a. Journal of Medicinal Chemistry 43 4370-4376.

Belsham DD, Cai F, Cui H, Smukler SR, Salapatek AM \& Shkreta L 2004 Generation of a phenotypic array of hypothalamic neuronal cell models to study complex neuroendocrine disorders. Endocrinology 145 393-400.

Frystyk J, Skjærbæk C, Vestbo E, Fisker S \& Ørskov H 1999 Circulating levels of free insulin-like growth factors in obese subjects: the impact of type 2 diabetes. Diabetes/Metabolism Research and Reviews 15 314-322.

Gauna C, Delhanty PJ, Hofland LJ, Janssen JA, Broglio F, Ross RJ, Ghigo E \& van der Lely AJ 2005 Ghrelin stimulates, whereas desoctanoyl ghrelin inhibits, glucose output by primary hepatocytes. Journal of Clinical Endocrinology and Metabolism 90 1055-1060.

Gualillo O, Lago F, Casanueva FF \& Dieguez C 2006 One ancestor, several peptides post-translational modifications of preproghrelin generate several peptides with antithetical effects. Molecular and Cellular Endocrinology 256 1-8.

Horvath TL, Diano S, Sotonyi P, Heiman M \& Tschop M 2001 Minireview: ghrelin and the regulation of energy balance - a hypothalamic perspective. Endocrinology 142 4163-4169.

Hosoda H, Kojima M, Matsuo H \& Kangawa K 2000a Ghrelin and des-acyl ghrelin: two major forms of rat ghrelin peptide in gastrointestinal tissue. Biochemical and Biophysical Research Communications 279 909-913.

Hosoda H, Kojima M, Matsuo H \& Kangawa K $2000 b$ Purification and characterization of rat des-Gln14-Ghrelin, a second endogenous ligand for the growth hormone secretagogue receptor. Journal of Biological Chemistry 275 21995-22000.

Hosoda H, Kojima M, Mizushima T, Shimizu S \& Kangawa K 2003 Structural divergence of human ghrelin. Identification of multiple ghrelin-derived molecules produced by post-translational processing. Journal of Biological Chemistry 278 64-70.

Jeffery PL, Herington AC \& Chopin LK 2002 Expression and action of the growth hormone releasing peptide ghrelin and its receptor in prostate cancer cell lines. Journal of Endocrinology 172 R7-R11.

Jeffery PL, Duncan RP, Yeh AH, Jaskolski RA, Hammond DS, Herington AC \& Chopin LK 2005 Expression of the ghrelin axis in the mouse: an exon 4-deleted mouse proghrelin variant encodes a novel C terminal peptide. Endocrinology 146 432-440.
Kamegai J, Tamura H, Shimizu T, Ishii S, Sugihara H \& Oikawa S 2004 Effects of insulin, leptin, and glucagon on ghrelin secretion from isolated perfused rat stomach. Regulatory Peptides 119 77-81.

Kawamura K, Sato N, Fukuda J, Kodama H, Kumagai J, Tanikawa H, Nakamura A, Honda Y, Sato T \& Tanaka T 2003 Ghrelin inhibits the development of mouse preimplantation embryos in vitro. Endocrinology 144 2623-2633.

Kojima M, Hosoda H, Date Y, Nakazato M, Matsuo H \& Kangawa K 1999 Ghrelin is a growth hormone-releasing acylated peptide from stomach. Nature 402 656-660.

van der Lely AJ, Tschop M, Heiman ML \& Ghigo E 2004 Biological, physiological, pathophysiological, and pharmacological aspects of ghrelin. Endocrine Reviews 25 426-457.

Luque RM \& Kineman RD 2006 Impact of obesity on the growth hormone axis: evidence for a direct inhibitory effect of hyperinsulinemia on pituitary function. Endocrinology 147 2754-2763.

Luque RM, Gahete MD, Valentine RJ \& Kineman RD 2006 a Examination of the direct effects of metabolic factors on somatotrope function in a non-human primate model, Papio anubis. Journal of Molecular Endocrinology 37 1-14.

Luque RM, Gahete MD, Hochgeschwender U \& Kineman RD $2006 b$ Evidence that endogenous somatostatin (SST) inhibits adrenocorticotropin (ACTH) and ghrelin expression by independent pathways. American Journal of Physiology. Endocrinology and Metabolism 291 E395-E403.

Luque RM, Park S \& Kineman RD 2007 Severity of the catabolic condition differentially modulates hypothalamic expression of growth hormone-releasing hormone (GHRH) in the fasted mouse; potential role of neuropeptide $\mathrm{Y}$ (NPY) and corticotropin-releasing hormone (CRH). Endocrinology 148 300-309.

Martin NM, Houston PA, Patterson M, Sajedi A, Carmignac DF, Ghatei MA, Bloom SR \& Small CJ 2006 Abnormalities of the somatotrophic axis in the obese agouti mouse. International Journal of Obesity 30 430-438.

Moesgaard SG, Ahren B, Carr RD, Gram DX, Brand CL \& Sundler F 2004 Effects of high-fat feeding and fasting on ghrelin expression in the mouse stomach. Regulatory Peptides 120 261-267.

Muccioli G, Pons N, Ghe C, Catapano F, Granata R \& Ghigo E 2004 Ghrelin and des-acyl ghrelin both inhibit isoproterenol-induced lipolysis in rat adipocytes via a non-type la growth hormone secretagogue receptor. European Journal of Pharmacology 498 $27-35$.

Nakae J, Kido Y \& Accili D 2001 Distinct and overlapping functions of insulin and IGF-I receptors. Endocrine Reviews 22 818-835.

Nakazato M, Murakami N, Date Y, Kojima M, Matsuo H, Kangawa K \& Matsukura S 2001 A role for ghrelin in the central regulation of feeding. Nature 409 194-198.

Nishi Y, Hiejima H, Mifune H, Sato T, Kangawa K \& Kojima M 2005 Developmental changes in the pattern of ghrelin's acyl modification and the levels of acyl-modified ghrelins in murine stomach. Endocrinology 146 2709-2715.

Pemberton C, Wimalasena P, Yandle T, Soule S \& Richards M 2003 C-terminal pro-ghrelin peptides are present in the human circulation. Biochemical and Biophysical Research Communications 310 567-573.

Ricart W \& Fernandez-Real JM 2001 No decrease in free IGF-I with increasing insulin in obesity-related insulin resistance. Obstetrica et Gynecologica 9 631-636.

Sugino T, Hasegawa Y, Kikkawa Y, Yamaura J, Yamagishi M, Kurose Y, Kojima M, Kangawa K \& Terashima Y 2002 A transient ghrelin surge occurs just before feeding in a scheduled meal-fed sheep. Biochemical and Biophysical Research Communications 295 255-260.

Tanaka M, Hayashida Y, Iguchi T, Nakao N, Nakai N \& Nakashima K $2001 a$ Organization of the mouse ghrelin gene and promoter: occurrence of a short noncoding first exon. Endocrinology 142 $3697-3700$ 
Tanaka M, Hayashida Y, Nakao N, Nakai N \& Nakashima K $2001 b$ Testisspecific and developmentally induced expression of a ghrelin genederived transcript that encodes a novel polypeptide in the mouse. Biochimica et Biophysica Acta 1522 62-65.

Toshinai K, Mondal SS, Nakazato M, Date Y, Murakami N, Kojima M, Kangawa K \& Matsukura S 2001 Upregulation of ghrelin expression in the stomach upon fasting, insulin-induced hypoglycemia, and leptin administration. Biochemical and Biophysical Research Communications 281 1220-1225.

Toshinai K, Yamaguchi H, Sun Y, Smith RG, Yamanaka A, Sakurai T, Date Y, Mondal MS, Shimbara T, Kawagoe T et al. 2006 Des-acyl ghrelin induces food intake by a mechanism independent of the growth hormone secretagogue receptor. Endocrinology 147 2306-2314.

Tschop M, Smiley DL \& Heiman ML 2000 Ghrelin induces adiposity in rodents. Nature 407 908-913.
Tschop M, Weyer C, Tataranni PA, Devanarayan V, Ravussin E \& Heiman ML 2001 Circulating ghrelin levels are decreased in human obesity. Diabetes 50 707-709.

Zhang JV, Ren PG, Avsian-Kretchmer O, Luo CW, Rauch R, Klein C \& Hsueh A 2005 Obestatin, a peptide encoded by the ghrelin gene, opposes ghrelin's effects on food intake. Science $\mathbf{3 1 0}$ 996-999.

Received 25 January 2007

Accepted 15 February 2007

Made available online as an Accepted Preprint 19 February 2007 